\title{
Sonographic Determination of Normal Spleen Size in Turkish Adults
}

\author{
Determinación Ecográfica del Tamaño Normal del Bazo en Adultos Turcos
}

Medih Çeliktas*; Sema Özandaç**; Pınar Göker*** \& Memduha Gülhal Bozkır**

ÇELIKTAS, M.; ÖZANDAÇ, S.; GÖKER, P. \& BOZKIR, M. G. Sonographic determination of normal spleen size in Turkish adults. Int. J. Morphol., 33(4):1401-1405, 2015.

SUMMARY: The current study was undertaken to determine normal spleen dimensions and anthropometric evaluation by ultrasonography from females and males in our population. These measurements were taken using an ultrasonography. The mean values of the age, height, weight and body mass index (BMI) of subjects, spleen width (SW), spleen length (SL), spleen thickness (ST) and spleen volume calculated with elipsoid formula; length $\mathrm{x}$ width $\mathrm{x}$ thickness $\mathrm{x} 0.524$ were taken. These measurements were found to be $36.37 \pm 10.83$ years, $164.22 \pm 4.72 \mathrm{~cm}, 60.26 \pm 7.11 \mathrm{~kg}, 22.30 \pm 2.09 \mathrm{~kg} / \mathrm{m}^{2}, 7.58 \pm 1.56 \mathrm{~cm}, 9.87 \pm 1.28 \mathrm{~cm}, 3.34 \pm 0.79 \mathrm{~cm}$ and $136.05 \pm 61.14$ $\mathrm{cm}^{3}$ in females respectively. Additionally, in males same dimensions were $40.50 \pm 12.77$ years, $174.41 \pm 6.57 \mathrm{~cm}, 76.33 \pm 8.54 \mathrm{~kg}, 25.06 \pm 2.10$ $\mathrm{kg} / \mathrm{m}^{2}, 8.75 \pm 1.84 \mathrm{~cm}, 11.01 \pm 1.186 \mathrm{~cm}, 4.12 \pm 1.09 \mathrm{~cm}$ and $220.70 \pm 115.35 \mathrm{~cm}^{3}$ respectively. The observations presented in this report have defined anatomic parameters about spleen size that need to be taken into consideration for reference data to determine population discrepancies and helpful for radiologists and clinicians.

KEY WORDS: Spleen length; Spleen width; Spleen thickness; Spleen volume.

\section{INTRODUCTION}

The spleen is the largest lymphoid organ with a parenchymal structure in the reticuloendothelial system and it is situated in the left hypocondrium (Danila, 2010; Lamp et al., 2002; Ehimwenma \& Tagbo, 2011). It is covered by the ribs (Danila). The shape of the spleen is tetrahedral or wedge (Ehimwenma \& Tagbo; Nayak et al., 2011). Moreover, the spleen size shows variations according to people, depending on the individual's height, age and sex (Danila; Hosey et al., 2006). Splenomegaly is an indicator of varieties of inflammatory, infectious, infiltrative, metabolic, neoplastic, hematopoietic diseases and the other diseases like portal hypertension, glycogen storage disorder, leukemia, lymphoma, melanoma, celiac disease (De Odorico et al., 1999; Mustapha et al., 2010; Asghar et al., 2011a). Furthermore, splenic enlargement may be result of especially viral illnesses and is an crucial criterion in diagnosing primary myeloproliferative diseases (Picardi et al., 2002; Spielmann et al., 2005). However, evaluation of splenic size by palpation can cause unreliable and wrong conclusions because spleen is not palpable untill it is enlarged 2 to 3 times its size (De Odorico et al.; Hosey et al.; Dhingra et al., 2010). The knowledge of spleen size, shape or external features might be of importance to surgeons and radiologists
(Nayak et al.). Ultrasonography is commonly used to diagnose splenomegaly and to determine the spleen size and it is safe, quick and reliable method for the calculation of splenic dimensions (Mustapha et al.; Dhingra et al.).

Therefore, the purpose of this study was to establish guidelines for normal splenic sizes in our healthy adults by using sonographic method and to compare our findings to other populations'data.

\section{MATERIAL AND METHOD}

The study was carried out from the 150 adult subjects (78 males and 72 females, ages 18 to 76 years) and oral statement were obtained from these subjects. All the test procedures were approved by the ethics committee. The patients selected for the study were evaluated with ultrasonography (USG) for abdominal and/or pelvic problems unrelated to the spleen, mostly because of urinary tract infection or abdominal pain. They had no history of disease related to the liver or splen and no gastrointestinal,

\footnotetext{
* Cukurova University Faculty of Medicine, Department of Radiology, Adana, Turkey.

** Çukurova University Faculty of Medicine, Department of Anatomy, Adana, Turkey.
} 


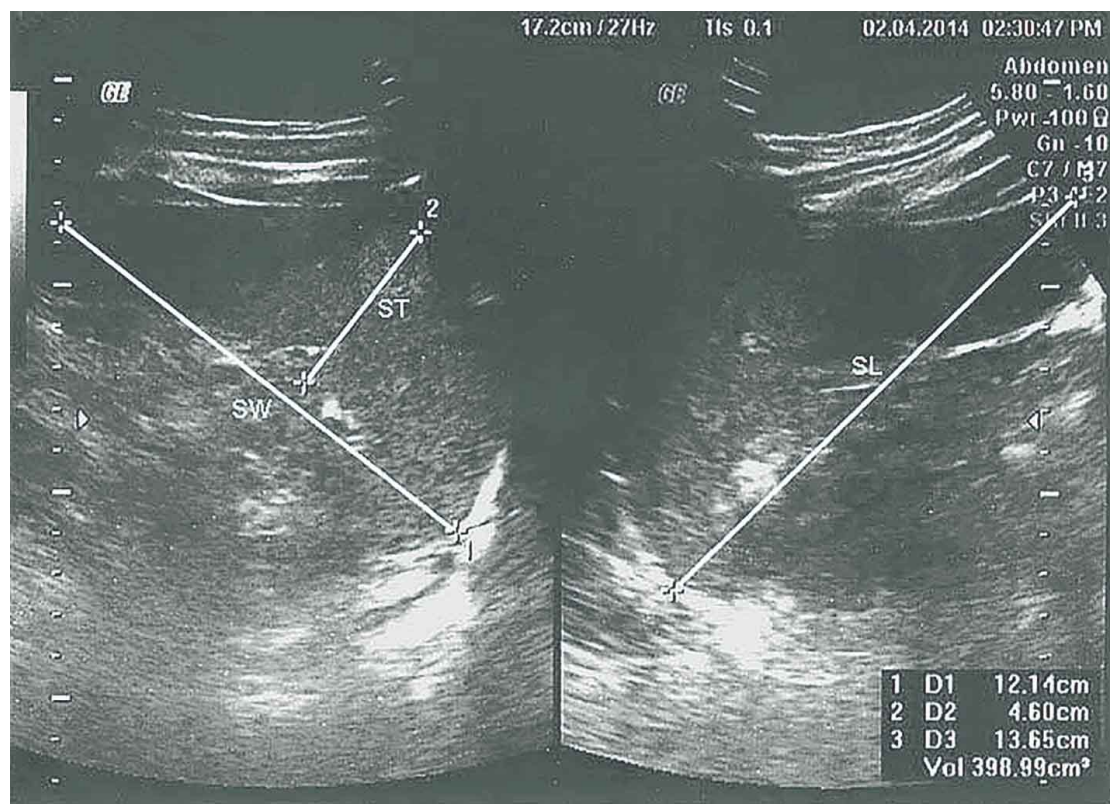

Fig. 1. Splenic length, thickness and width measurement methods used in this study. SW= Splenic width, ST= Splenic thickness, SL= Splenic length.

hematologic, oncologic or traumatic conditions. Anthropometric data, including sex, age, height and weight was recorded from each subject and body mass index was calculated according to the formula BMI $=$ weight $/$ height $^{2}$. All examinations were performed by radiologist and anatomist in abdominal ultrasonography using a commercially available high-resolution real time US scanner (GE Voluser,730 USA) with a $3.5 \mathrm{MHz}$ sector transducer. Moreover, images were obtained with the subject lying in the supine or slightly right lateral decubitus position and through an oblique intercostal approach following suspended deep inspiration. Splenic length, thickness, width and volume were obtained as follows: splenic length was defined as the maximum distance between the dome of the spleen and tip of the spleen on a longitudinal section in the sagittal plane) (SL), splenic width was defined as the maximum distance between the medial and lateral borders of the spleen (it was measured in a plane perpendicular to the length) (SW); splenic thickness was defined as the distance between the inner and outer surface (it was measured at the level of the splenic hilum on a transverse section) (ST) and splenic volume was calculated with the following standard elipsoid formula as; $0.524 \mathrm{x}$ width $\mathrm{x}$ length $\mathrm{x}$ thickness. Splenic length, thickness and width measurement methods were shown in Figure 1.

The data were divided into two groups: female and male. The SPSS 13.0 program was used for statistical analysis of the measurement results. From these measurements, Means, standard deviations (SD), and minimum and maximum values were calculated.

\section{RESULTS}

The minimum-maximum, Mean and standard deviations values of the measurements from female and male spleen are shown in Table I.

Table I. Characteristics of spleen from 150 subjects (78 males and 72 females ages 18-76 years).

\begin{tabular}{lcccc}
\hline \multirow{2}{*}{ Parameters } & \multicolumn{2}{c}{ Females $(\mathbf{n}=\mathbf{7 8})$} & \multicolumn{2}{c}{ Males (n= 72) } \\
\cline { 2 - 5 } & Mean \pm SD & Min - Max & Mean \pm SD & Min - Max \\
\hline Age (years) & $36.37 \pm 10.83$ & $19-63$ & $40.50 \pm 12.77$ & $18-76$ \\
Height (cm) & $164.22 \pm 4.72$ & $155-178$ & $174.41 \pm 6.57$ & $162-188$ \\
Weight (kg) & $60.26 \pm 7.11$ & $45-75$ & $76.33 \pm 8.54$ & $62-103$ \\
Body Mass Index (BMI) (kg/m $)$ & $22.30 \pm 2.09$ & $16.40-26.60$ & $25.06 \pm 2.10$ & $20.50-35.60$ \\
Splenic Width (cm) (SW) & $7.58 \pm 1.56$ & $4.70-13.40$ & $8.75 \pm 1.84$ & $4.20-13$ \\
Splenic Length (cm) (SL) & $9.87 \pm 1.28$ & $6.90-12.70$ & $11.01 \pm 1.186$ & $8.40-14.00$ \\
Splenic Thickness (cm) (ST) & $3.34 \pm 0.79$ & $1.70-5.40$ & $4.12 \pm 1.09$ & $1.90-7.10$ \\
Splenic Volume** & $136.05 \pm 61.14$ & $30.11-302.62$ & $220.70 \pm 115.35$ & $56.70-599.91$ \\
\hline
\end{tabular}




\section{DISCUSSION}

The spleen which filters the unwanted elements from blood by phagocytosis, is located in the abdomen, below the diaphragm and connected to the stomach. Moreover it is an important lymphoid organ and plays an crucial role in the immune responses (Mebius \& Kraal, 2005; Chaware et al., 2012). Splenic size can be used as an indicator of disease activity in a variety of disorders of the reticuloendothelial system and many disorders alter splenic size including infective, infestation, infiltrative, immunologic and malignant conditions. However, the physical examination is unreliable to evaluate the splenic enlargement (Ehimwenma \& Tagbo; Lamp et al.; Spielmann et al.). Moreover, it has been reported that the presence of the colon, stomach and lung near the spleen makes the examination difficult. But, the intercostal approach permits a good examination (Danila). Ultrasonography (USG) is usually used for the diagnosis of the splenomegaly. Additionally, US measurement of splenic size is standard application and it provides a objective way ofnoninvasive examination of the spleen. It is especially useful because of lack of radiation exposure (Ehimwenma \& Tagbo; Lamp et al.; Hosey et al.; Mustapha et al.; Megremis et al., 2004; Mittal \& Chowdhary, 2010). Thus, it is safe, quick and accurate method for measurement of splenic dimensions (Picardi et al.; Dhingra et al., 2010; Megremis et al.; Mittal \& Chowdhary). Moreover, the spleen size is exposed to many variations at different periods of life, in different individuals, and in the same individual under different conditions. It can vary from individual, depending on the individual's height, age and sex (Danila; Hosey et al.).

The information of anamalous size, shape or external features of the spleen could be of important for surgeons and radiologists (Nayak et al.). Moreover, splenomegaly is a crucial clinical sign. Because it might be the only manifestation of a serious underlying disease such as lymphoma and other hematologic diseases (De Odorico et al.; Loftus et al., 1999). Furthermore, it was reported that spleen length was related to age, height, weight and body surface area (Megremis et al.). During the growth duration from infancy to adolescence, development of visseral organs like spleen demonstrated correlation with increases in height, weight and body surface area. Additionally, it was estimated that splenic length measured by ultrasonography provided an objective and safe method to evaluate spleen size (Hosey et al.; Megremis et al.; Konus et al., 1998).

In this study, we measured the splenic length, width, thickness and volume (calculated with formula in adults and compared our results to other populations. The mean values of splenic length and width were $9.91 \mathrm{~cm}$ and $4.74 \mathrm{~cm}$ in females and $11.29 \mathrm{~cm}$ and $5.54 \mathrm{~cm}$ in males in U.S.A. respectively whereas, same values were $10.1 \mathrm{~cm}, 4.0 \mathrm{~cm}$ in females and $11.1 \mathrm{~cm}, 4.4 \mathrm{~cm}$ in males in Nigerians respectively (Ehimwenma \& Tagbo; Hosey et al.). However, corresponding values were as $8.9 \mathrm{~cm}$ and $4.9 \mathrm{~cm}$ in Africans (Mustapha et al.). Moreover, same values were found to be $9.34 \mathrm{~cm}$ and $3,45 \mathrm{~cm}$ in females $9.40 \mathrm{~cm}$ and $3.45 \mathrm{~cm}$ in males in Rajasthan population respectively (Mittal \& Chowdhary). These dimensions were $10.34 \mathrm{~cm}$ and 5.61 in females and $10.91 \mathrm{~cm}$ and $9.74 \mathrm{~cm}$ in males in North Indians and $7.68 \mathrm{~cm}$ and $8.5 \mathrm{~cm}$ in Thai adults respectively (Asghar et al., 2011b; Srisajjakul et al., 2012). However, the mean splenic length was found as between $8.84 \mathrm{~cm}$ in Chinese population (Loftus et al.). When we analyze our data including splenic length (SL) and splenic width (SW) were found to be $9.87 \mathrm{~cm}$ and $7.58 \mathrm{~cm}$ in females respectively and in males as $11.01 \mathrm{~cm}$ and $8.75 \mathrm{~cm}$ respectively. We found differences in the mean values of splenic length of above studies except U.S.A. with our population: The Africans, Rajasthan population and Thai population having lower, and Nigerians having greater values than us. Our results are different from to those of these investigations, except the Thai population when comparing splenic width results. Moreover, mean values of splenic thickness was reported between $3.33 \mathrm{~cm}$ and $6 \mathrm{~cm}$ in Thai population, Indians, Africans, Americans and Nigerians (Mustapha et al.; Asghar et al., 2011b; Srisajjakul et al.; Tonelli et al., 2013). In this study this value was $4.12 \mathrm{~cm}$ in males, and $3.34 \mathrm{~cm}$ in females. According to this data our result is similar to Thai population.

Splenic volume is calculated using with standard ellipsoid formula ( $0.524 \mathrm{x}$ width $\mathrm{x}$ length $\mathrm{x}$ thickness). This formula is often used for predicting the volume of many irregularly shaped organs (Asghar et al., 2011b; Yetter et al., 2003; Sonmez et al., 2007). In literature findings, it was seen that elipsoid formula was used. It was found to be 220.70 $\mathrm{cm}^{3}$ (measured with standard elipsoid formula) in males and $136.05 \mathrm{~cm}^{3}$ in females. In a studying consisting of Nigerians, in males mean value of splenic volume were $202.7 \mathrm{~cm}^{3}$ and in females $153.7 \mathrm{~cm}^{3}$ respectively (Ehimwenma \& Tagbo). Moreover, the same value was $119.5 \mathrm{~cm}^{3}$ in African population (Mustapha et al.). Asgar et al. (2011a) determined that the splenic volume were $288.36 \mathrm{~cm}^{3}$ and $217.44 \mathrm{~cm}^{3}$ in males and females respectively. Furthermore, the mean volume of the spleen were $132 \mathrm{~cm}^{3}$ and $113 \mathrm{~cm}^{3}$ respectively in Japanese males and females whereas, same dimensions were $134.2 \mathrm{~cm}^{3}$ and $115.6 \mathrm{~cm}^{3}$ in males and females respectively in Thai adults (Srisajjakul et al.; Kaneko et al., 
2008). However, same value was $344 \mathrm{~cm}^{3}$ in USA (Tonelli et al.). Due to these data, we found differences in the mean values of splenic volume of Nigerians, Africans, Japanese population, Thai population and USA population with our population: The Thai, Japans and Africans having lower, and USA having greater values than ours.

In summary, when comparing the literature findings with this study, we observe that there are differences between Nigerians, Africans, Chinese population, Rajasthani population, Indians and our population data. However, there are similiarities between Thai and our population results. We consider that these discrepancies could be a result of such factors like race, genetic variables, nutritional status, socioeconomic status and demographic variables including age, weight and height. Moreover, we found that all dimensions were greater in males than females and splenic length decreased with increase in age in both genders. As we mentioned before, there was no differences in the mean values of the spleen volume between two calculation methods.

In conclusion, we think that the precise knowledge of the spleen morphology with USG may be essential for safe and accurate diagnose of many disorders such as infections, splenomegaly, malignant conditions and viral illnesses for surgeons and radiologist. Therefore, the observations presented in this study have defined anatomic parameters that need to be taken into consideration for evaluate splenic problems and guidelines for determine the reference values. As a result, we believe that the data obtained in this study can provide crucial information for surgeons and radiologists about spleen and they can be used as reference values for evaluating pathologic changes in the spleen region.

ÇELIKTAS, M.; ÖZANDAÇ, S.; GÖKER, P. \& BOZKIR, M. G. Determinación ecográfica del tamaño normal del bazo en adultos turcos. Int. J. Morphol., 33(4):1401-1405, 2015.

RESUMEN: El objetivo fue determinar las dimensiones normales del bazo y realizar una evaluación antropométrica mediante ecografía en mujeres y hombres turcos. Fueron calculados los valores medios de edad, altura, peso, índice de masa corporal (IMC), ancho del bazo (AB), longitud del bazo (LB) y grosor del bazo (GB), junto al volumen del bazo mediante la fórmula elipsoide (largo $\mathrm{x}$ ancho $x$ grosor $x$ 0,524). Las mujeres presentaron una edad de 36,37 $\pm 10,83$ años, altura de 164,22 $\pm 4,72 \mathrm{~cm}$, peso de $60,26 \pm 7,11 \mathrm{~kg}$, IMC

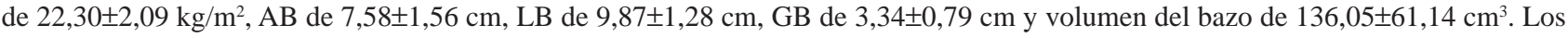
hombres presentaron una edad de 40,50 $\pm 12,77$ años, altura de $174,41 \pm 6,57 \mathrm{~cm}$, peso de $76,33 \pm 8,54 \mathrm{~kg}, \mathrm{IMC} \mathrm{de} 25,06 \pm 2,10 \mathrm{~kg} / \mathrm{m}^{2}, \mathrm{AB}$ de $8,75 \pm 1,84 \mathrm{~cm}$, LB de $11,01 \pm 1,186 \mathrm{~cm}$, GB de 4,12 $\pm 1,09 \mathrm{~cm}$ y volumen del bazo de $220,70 \pm 115,35 \mathrm{~cm}^{3}$. Nuestras observaciones han definido parámetros anatómicos sobre el tamaño del bazo, los cuales deben ser considerados como datos de referencia para determinar las discrepancias en la población, de utilidad para radiólogos y clínicos.

PALABRAS CLAVE: Longitud del bazo; Ancho del bazo; Grosor del bazo; Volumen del bazo.

\section{REFERENCES}

Asghar, A.; Agrawal, D.; Yunus, S. M.; Sharma, P. K.; Zaidi, S. H. \& Sinha, A. Standard Splenic Volume Estimation in North Indian Adult Population: Using 3D Reconstruction of Abdominal CT Scan Images. Anat. Res. Int., 2011:707325, 2011a.

Asghar, A.; Naaz, S.; Agrawal, D. \& Sharma, P. K. Morphometric study of spleen in North Indian adult population: CT Scan image based study. J. Clin. Diagn. Res., 5(5):974-7, 2011 b.

Chaware, P. N.; Belsare, S. M.; Kulkarni, Y. R.; Pandit, S. V. \& Ughade, J. M. Variational anatomy of the segmental branches of the splenic artery. J. Clin. Diagn. Res., 6(3):336-8, 2012.

Danila, M. The ultrasound examination of the spleen. Med. Ultrason., 12(3):253-4, 2010.

De Odorico, I.; Spaulding, K. A.; Pretorius, D. H.; Lev-Toaff, A. S.; Bailey, T. B. \& Nelson, T. R. Normal splenic volumes estimated using three-dimensional ultrasonography. $J$. Ultrasound Med., 18(3):231-6, 1999.
Dhingra, B.; Sharma, S.; Mishra, D.; Kumari, R.; Pandey, R. M. \& Aggarwal, S. Normal values of liver and spleen size by ultrasonography in Indian children. Indian Pediatr., 47(6):487-92, 2010.

Ehimwenma, O. \& Tagbo, M. T. Determination of normal dimension of the spleen by ultrasound in an endemic tropical environment. Niger. Med. J., 52(3):198-203, 2011.

Hosey, R. G.; Mattacola, C. G.; Kriss, V.; Armsey, T.; Quarles, J. D. \& Jagger, J. Ultrasound assessment of spleen size in collegiate athletes. Br. J. Sports Med., 4O(3):251-4, 2006.

Kaneko, J.; Sugawara, Y.; Matsui, Y. \& Makuuchi, M. Spleen size of live donors for liver transplantation. Surg. Radiol. Anat., 30(6):515-8, 2008.

Konus, O. L.; Ozdemir, A.; Akkaya, A.; Erbas, G.; Celik, H. \& Isik, S. Normal liver, spleen, and kidney dimensions 
in neonates, infants, and children: evaluation with sonography. AJR Am. J. Roentgenol., 171(6):1693-8, 1998.

Lamp, P. M.; Lund, A.; Kanagasabay, R. R.; Martin, A.; Webb, J. A. \& Reznek, R. H. Spleen size: how well do linear ultrasound measurements correlate with three-dimensional CT volume assessments? Br. J. Radiol., 75(895):573-7, 2002.

Loftus, W. K; Chow, L. T. \& Metreweli, C. Sonographic measurement of splenic length: correlation with measurement at autopsy. J. Clin. Ultrasound, 27(2):71-4, 1999.

Mebius, R. E. \& Kraal, G. Structure and function of the spleen. Nat. Rev. Immunol., 5(8):606-16, 2005.

Megremis, S. D.; Vlachonikolis, I. G. \& Tsilimigaki, A. M. Spleen length in childhood with US: normal values based on age, sex, and somatometric parameters. Radiology, 231(1):129-34, 2004.

Mittal, R. \& Chowdhary, D. S. A pilot study of the normal measurements of the liver and spleen by ultrasonography in the Rajasthani population. J. Clin. Diagn. Res., 4(4):2733-6, 2010.

Mustapha, Z.; Tahir, A.; Tukur, M.; Bukar, M. \& Lee, W. K. Sonographic determination of normal spleen size in an adult African population. Eur. J. Radiol., 75(1):e133-5, 2010.

Nayak, B. S. ; Somayaji, S. N. \& Soumya, K. V. A study on the variations of size, shape and external features of the spleen in South Indian population. Int. J. Morphol., 29(3):675-7, 2011.

Picardi, M.; Martinelli, V.; Ciancia, R.; Soscia, E.; Morante, R.; Sodano, A.; Fortunato, G. \& Rotoli, B. Measurement of spleen volume by ultrasound scanning in patients with thrombocytosis: a prospective study. Blood, 99(11):4228-30, 2002.

Sonmez, G.; Ozturk, E.; Basekim, C. C.; Mutlu, H.; Kilic, S.; Onem, Y. \& Kizilkaya, E. Effects of altitude on spleen volume: sonographic assessment. J. Clin. Ultrasound, 35(4):182-5, 2007.

Spielmann, A. L.; DeLong, D. M. \& Kliewer, M. A. Sonographic evaluation of spleen size in tall healthy athletes. AJR Am. J. Roentgenol., 184(1):45-9, 2005.

Srisajjakul, S.; Prapaisilp, P. \& Laorratkul, N. Normal splenic volume assessment on CT in 426 adults. Siriraj Med. J., 64(2):43-6, 2012.

Tonelli, A. R; Yadav, R.; Gupta, A.; Arrossi, A. V.; Heresi, G. A. \& Dweik, R. A. Spleen size in idiopathic and heritable pulmonary arterial hypertension. Respiration, 85(5):391-9, 2013.

Yetter, E. M.; Acosta, K. B.; Olson, M. C. \& Blundell, K. Estimating splenic volume: sonographic measurements correlated with helical CT determination. AJR Am. J. Roentgenol., 181(6):1615-20, 2003.

\author{
Correspondence to: \\ Sema Özandac \\ Cukurova University Faculty of Medicine \\ Department of Anatomy \\ Adana \\ TURKEY
}

Email: sezaoz@hotmail.com

Received: 19-05-2015

Accepted: 02-09-2015 